\title{
Dynamic Behavior of Three phase Inductions Motors as Loads in an Electric Power System with Distributed Generation, a Case of Study.
}

\author{
Marcelo Rodrigo García Saquicela, Ernesto Ruppert Filho, José Luis Azcue Puma. \\ School of Electrical and Computer Engineering, State University of Campinas (UNICAMP), Campinas, SP, Brazil \\ Email:\{Ernesto Ruppert Filho\} ruppert@fee.unicamp.br \{José Luis Azcue Puma\} jose.azcue@ufabc.edu.br
}

\begin{abstract}
One of the basics characteristics of a power electric system is guarantee the power supply to the loads reliable and uninterrupted, the modern power systems have minimal conditions for proper operation, one of studies of major concern is stability. The studies most considering the electric power system as a whole, taking into account elements that affect their behavior, mainly including the dynamic model of the loads. Within industrial environments loads are formed by three phase induction motors, these loads must be modeled dynamically in detail to be possible a faithful study of the system and its real influence into the power system. Will be made dynamic tests into am industrial electric power system selected to verify the influence of induction motor loads, the motors also are controlled with DTC technique and the system can operate with internal generation.
\end{abstract}

\section{INTRODUCTION}

Most of analyses of electric power systems are made with statics methods like P-V curves, the dynamic of the loads doesn't are taken in count. According [1] the margins reductions of active power into $\mathrm{P}-\mathrm{V}$ curves when the portion of loads composed by induction motors increases is because this type of loads have voltage dependence with the consumption of reactive power that are the typical behavior of this kind of loads. This is the reason why some researches talk about that systems composes with induction motors loads may represent a problem in terms of stability, if a disturb occur like short circuit of a loss of grid, this kind of loads may leave to the system to an unappropriated behavior [2].

The dynamic simulation of the nonlinear behavior of an electric system provides a reproduction more accurate of the phenomenon that occurs on a power grid. Meanwhile this analysis involves high computational cost, and don't show information about stability margins of the system. Its application is restricted to studies of coordination of control and protection devices, in specific situation of voltage collapse. [3].

For this reason, this work shows the dynamic simulation of a facility power electric system with three phase's induction motors as main loads, to look out the influence with and without control of the electromagnetic torque and activate internal power generation, as a case of distributed generation. The power grid under analysis belongs to a mining factory and the large induction motors correspond to stone crushers.

\section{SYSTEM MODEL}

\section{A. Description of the industrial electric power system}

The industrial unit is formed for a substation, transformers, breakers, constant impedance loads, synchronous machines, electric power lines, three phase induction motors and its respective controls, based on [4]. The facility referred is located in São Paulo Brazil, rearranged for the study purpose like a mining factory with four three phase induction motors operating as stone crushers, the industrial grid have three salient poles synchronous machines, each one of 6.25 MVA, the induction machines are $2250 \mathrm{hp}$ squirrel cage.

The substation has a short circuit level of 300 MVA, delivering a voltage of $138 \mathrm{kV}$, the power system is composed for loads modeled like constant impedance and the induction motors, the operation of the synchronous generators can be consider a case of distributed generation.

Fig. 1 illustrates a power grid under study. 


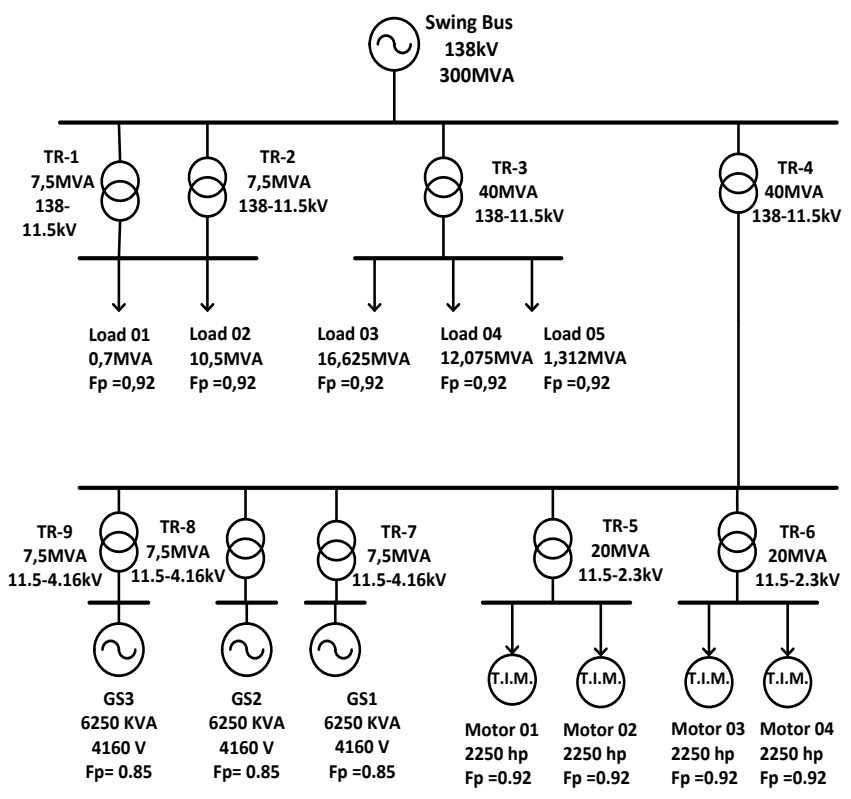

Fig. 1. Diagram of the industrial electrical power system

\section{B. Dynamic model of three phase induction motor}

The dynamic behavior of the three phase induction motor (T.I.M.) is governed by a set of differentials equations that can be placed in space vector form [5]. These equations show the relationship between linkages fluxes with estator and rotor windings with electrical currents and voltages of these windings.

The differentials equations of estator and rotor voltages, can be represented on the stationary reference frame, system used in the simulations, are shown below (1.1) to (1.4), using the definition of the voltage space vector, the current space vector and the magnetic flux space vector with the stator and rotor windings. the letter $\mathrm{s}$ is used for the stator variables and the letter $r$ is used for the rotor variables.

$u_{s}=R_{s} i_{s}+\frac{d \psi_{s}}{d t}$

$u_{r}^{\prime \rightarrow}=R_{r} i_{r}^{\prime \rightarrow}+\frac{d \psi_{r}^{\prime}}{d t}-j \omega_{r} \psi_{r}^{\prime \rightarrow}$

$\psi_{s}=L_{s} i_{s}+L_{m} i_{r}^{\prime \rightarrow}$ $\psi_{r}^{\prime \rightarrow}=L_{r} i_{r}^{\prime \rightarrow}+L_{m} i_{s}$

The compact form of these equations makes their application extremely convenient. The first terms of the equations (1.1) and (1.2) represents the voltage drops into the electrical resistances of the stator and rotor windings respectively. The second term represents the electromotive force of transformation of each winding, which are the first derived of the spatial vectors of the linkage magnetic fluxes with the stator and rotor.

Finally the term $-j \omega_{r} \psi_{r}^{\prime \rightarrow}$, represent the rotational electromotive force on the rotor produced by its rotation within the rotating magnetic field made by the stator currents.

The equations (1.1) to (1.4) are written in the form of spatial vectors of the linkage magnetic fluxes with the stator and rotor respectively.

The spatial vectors of the currents, linkages fluxes and voltages of stator winding into the stationary reference frame are represented by:

$$
\begin{gathered}
\begin{array}{l}
i_{s}=\frac{2}{3}\left[i_{a s}(t)+i_{b s}(t) \cdot a+i_{c s}(t) \cdot a^{2}\right]= \\
j i_{q s}+
\end{array} \\
\begin{array}{c}
\psi_{s} \vec{s}=\frac{2}{3}\left[\psi_{a s}(t)+\psi_{s} B(t) \cdot a+\psi_{s} C(t) \cdot a^{2}\right] \\
=\psi_{d s}+j \psi_{q s}
\end{array} \\
\begin{array}{c}
u_{s}=\frac{2}{3}\left[u_{a s}(t)+u_{b s}(t) \cdot a+u_{c s}(t) \cdot a^{2}\right] \\
u_{d s}+j u_{q s}
\end{array}
\end{gathered}
$$

\section{Control of three-phase induction motor}

For controlling of large induction motors was adopted the strategy based on direct torque control (DTC) using space vector modulation [6]. This control strategy uses the orientation of magnetic field by the stator flux for independent control of electromagnetic torque. According [7], can be use a two level inverter for controlling a motor of large scale (until $4160 \mathrm{~V}$ ) and it was implemented in this work. Others control strategies, like Direct Self Control can also be used. 


\section{Direct torque control of three-phase induction machine}

The purpose in the direct torque control is manipulate directly the stator flux linkage vector and the electromagnetic torque by the appropriated selection of the switching activation vectors of the feeding three-phase induction motor. The vectors selections are made restricting errors of the electromagnetic torque and the stator flux within two PI controllers, to achieve a quick answer of the electromagnetic torque, an acceptable switching frequency and low harmonic losses. DTC allows a quick response of the electromagnetic torque. In the symmetric three phase induction motor, one of the forms of representation of electromagnetic torque is through vector product between the spatial flux vector of flux linkage and stator current vector.

$$
T_{e m}=\frac{3}{2} P \psi_{s} \times \overrightarrow{i_{s}}
$$

Wherein $\psi_{s}$ and $i_{s}$ are the spatial vectors of the flux linkage and stator current respectively, $\mathrm{P}$ is the number of pole pairs. Into (1.8) both vectors are represented into the stationary reference frame. We have to consider $\psi_{s} \vec{s}=\left|\psi_{s}\right| e^{j \rho_{s}}$ and $i_{s}=$ $\left|i_{s}\right| e^{j \alpha_{s}}$, where $\rho_{s}$ and $\alpha_{s}$ are the angles of the spatial vectors of the flux linkage and stator current in relationship with the real axe of the reference frame system, then from the equation, it follows that:

$$
\begin{aligned}
& T_{e m}=\frac{3}{2} P\left|\psi_{s}\right|\left|i_{s}\right| \sin \left(\alpha_{s}-\rho_{s}\right) \\
& =\frac{3}{2} P\left|\psi_{s}\right|\left|i_{s}\right| \sin (\alpha)
\end{aligned}
$$

Wherein $\alpha=\alpha_{s}-\rho_{s}$ is the angle between the spatial vectors of flux linkage and the stator current. If an adequate voltage must be applied into the stator in such a way to keep the stator flux constant and the same could get a quick change in the angle $\rho_{s}$, then the electromagnetic torque will vary rapidly. If the angle increase, will produce a positive electromagnetic torque, but, if the angel decrease, will produce a reduction of the electromagnetic torque.

In conclusion, to control the spatial vector of the stator flux (module and angle) is necessary to generate an appropriate voltage vector through the inverter that feeds the three-phase induction motor.

\section{SIMULATION AND RESULTS}

Several teste were made, divided into scenarios, feeding the system with only the substation power supply, with and without electronic converters activating the induction machines, and feeding the system with the power of the substation and the synchronous generators.

\section{A. First scenario}

In this first group of tests, the conditions are that the industrial electric system is supplied only by the substation connection, without intervention of the synchronous generators. Two cases are compared, the first one without direct torque control of the four three-phase induction motors, and the other one with direct torque control of the inductive machines.

We noted that currents in the substation are different in case one and in case two, as shown;

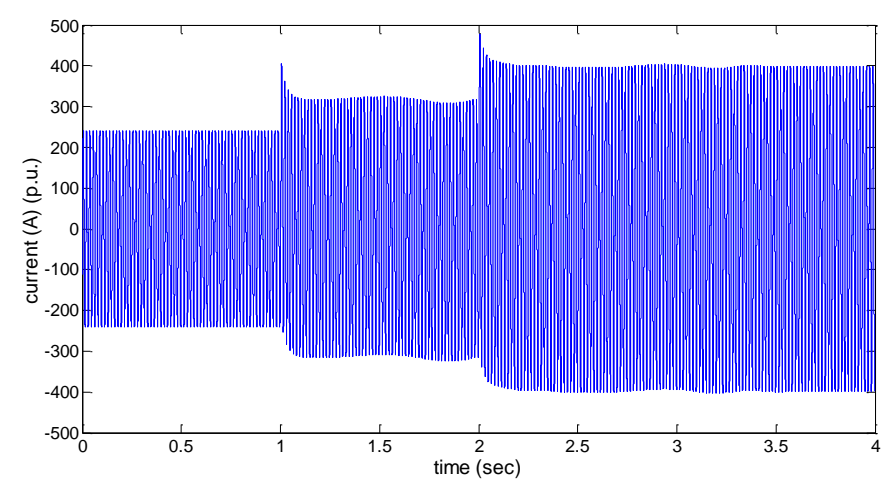

Fig. 2. Current delivered by the substation without DTC control of induction machines.

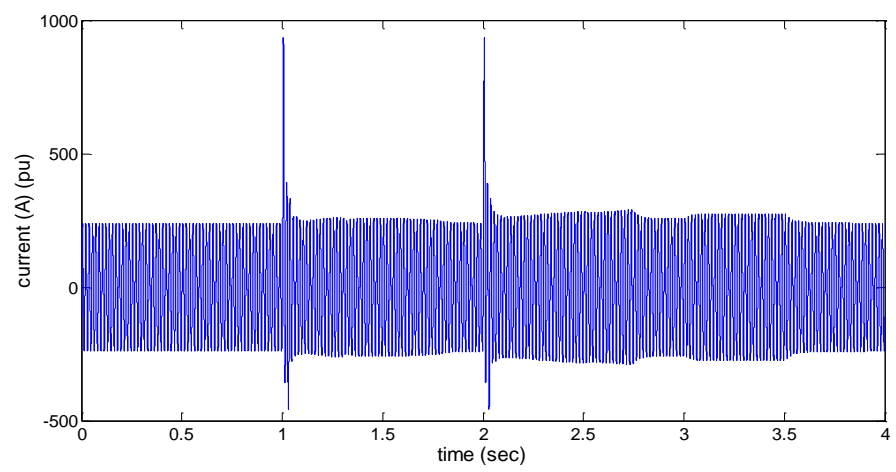

Fig. 3. Current delivered by the substation with DTC control of induction machines. 
We divided the industry power system into two blocks of inductive loads, each block formed by two inductive motors, each motor of $2250 \mathrm{hp}$, $2300 \mathrm{~V}$ and $1.78 \mathrm{MVA}$. As we can see in figure 2 and figure 3 , these two blocks of motors are activated in different times, $\mathrm{t}=1$ second and $\mathrm{t}=2$ seconds, the given current in the first case is about $533.4 \mathrm{~A}(\mathrm{pu})$ and in the second case is about 325.4 $\mathrm{A}(\mathrm{pu})$.

In the first case, the electromagnetic torque of the machines is not controlled, like we see in the next figure.

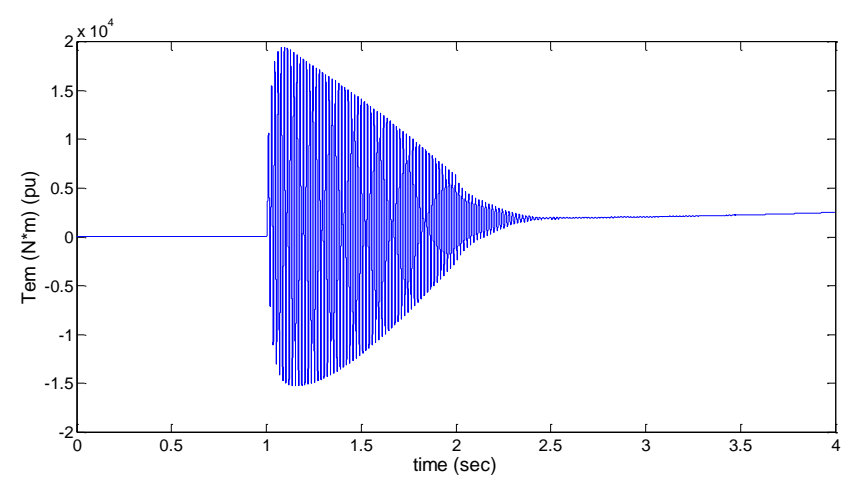

Fig. 4. Electromagnetic torque without control

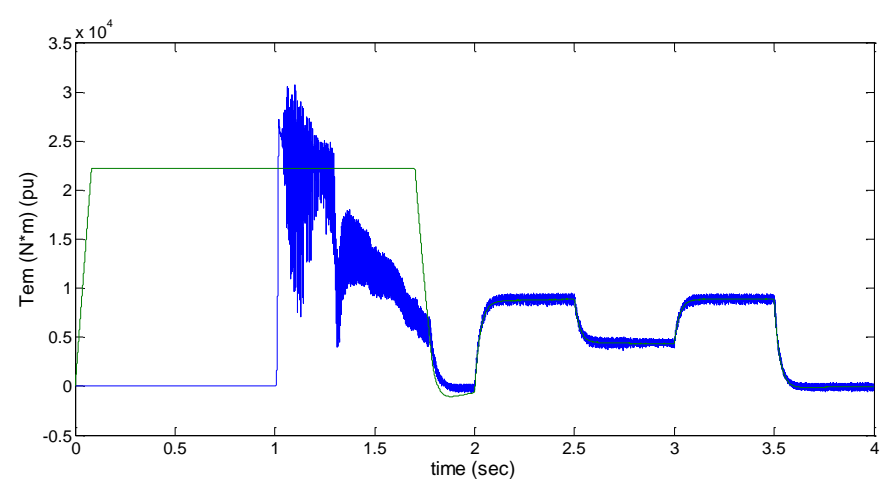

Fig. 5. Electromagnetic torque with control.

As we can see in the figure 5 , the generated electromagnetic torque (blue) follows very well the reference torque (green), in general with the DTC control takes about one second to stabilize the torque of the induction machine, without DCT, it takes about two seconds.

\section{B. Second Scenario}

In this second scenario the industry is supplied by the distributed generators and the power of the substation, it was verified that in all buses the voltage increase about $3 \%$, because the system has more energy reserves, thanks to the synchronous generators of salient poles.

The reactive power consumed in the system without DTC control is bigger than the system with DTC control of the three phase motors.

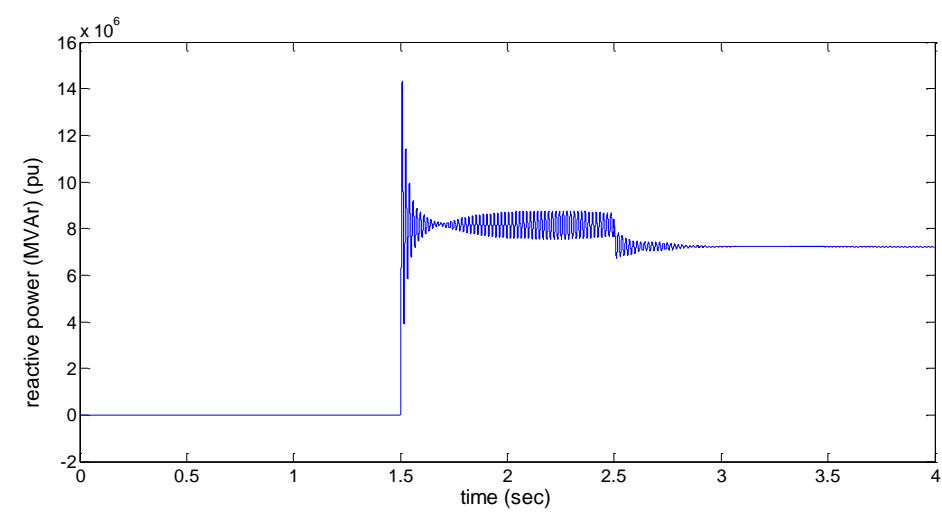

Fig. 6. Reactive power in induction machines without DTC control.

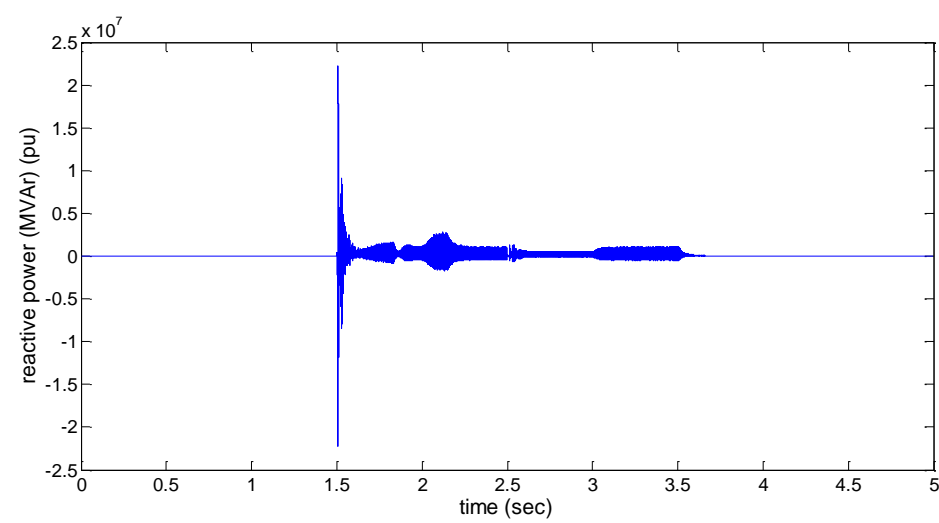

Fig. 7. Reactive power in induction machines with DTC control.

The electromagnetic torque of figure 8 without control, takes about 1.2 seconds to stabilize 


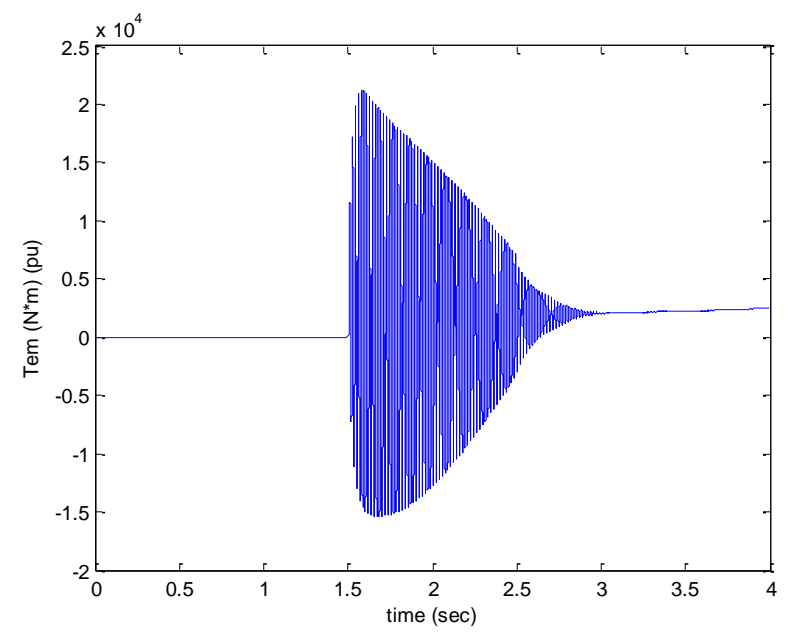

Fig. 8. Electromagnetic torque

In the other hand, with the control of torque, the machine takes about 0.65 seconds to stabilize the electromagnetic torque.

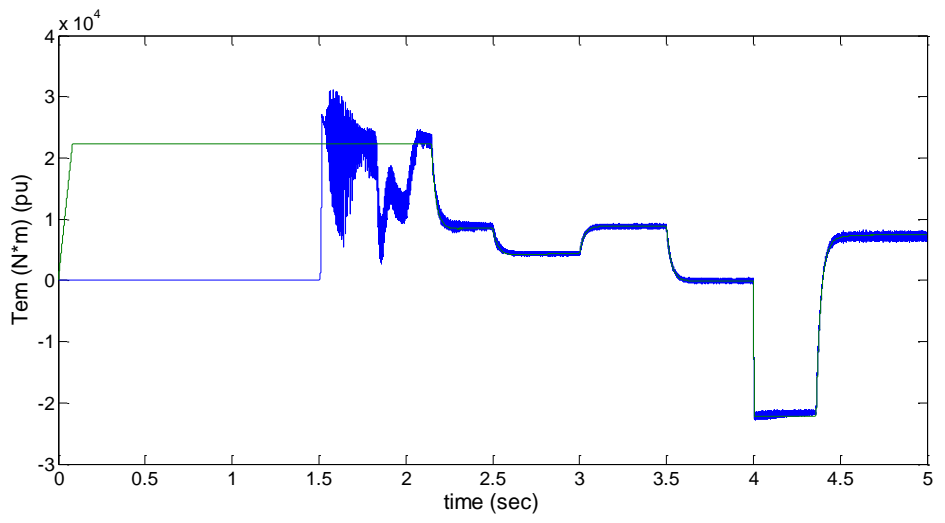

Fig. 9. Controlled electromagnetic torque.

\section{CONCLUSIONS}

When the system was simulated with the direct torque control (DTC), the reactive power consumed by the induction motors decrease, but the active power increase. The system present more stability when operates with the DTC control over the machinery and the distributed generators. The electromagnetic torque shows a quick response with the control applied as expected, in some applications like mine industry it is recommended for an optimal performance of the process.

\section{REFERENCES}

[1] L. P. da Silva, V. da Costa, "Voltage stability including detailed induction motor models" IEEE Trans. On industry application, Jun. 2011.

[2] L. Peng, "Study on the voltage stability of induction motor load," IEEE PES, Power System conference and exposition, 2004.

[3] Kundur, Power System Stability and Control,3th edition. McGraw-Hill Education, 1994.

[4] F. C. Lima Trindade, "Analysis of Protection Systems and Control

Industrial facilities with Synchronous Generators During islanded operation" UNICAMP, February 2009.

[5] P. C. Krause, Analysis of Electric Machinery and Drive Systems, IEEE press.

[6] T. G. Habetler, F. Profumo, 'Direct torque control of induction machines using space vector modulation', IEEE Trans, vol. 28, No. 5, October 1992.

[7] B. Wu, High Power Converters and AC Drives, IEEE press, 2006. 